\title{
Generation of tumor antigen-specific CD4+ and CD8+ T cells by simultaneous MHC-I and -II epitope presentation in vitro and in vivo
}

\author{
Carina Wehner ${ }^{1 *}$, Christian Ellinger ${ }^{1}$, Silke Raffegerst ${ }^{1}$, Susanne Wilde ${ }^{1}$, Barbara Mosetter $^{2}$, Judith Eckl ${ }^{1}$, \\ Bernhard Frankenberger ${ }^{2}$, Manon Weis ${ }^{1}$, Giulia Longinotti ${ }^{1}$, Nadja Sailer $^{1}$, Dolores J Schendel ${ }^{1}$, Slavoljub Milosevic ${ }^{1}$
}

From Society for Immunotherapy of Cancer 29th Annual Meeting

National Harbor, MD, USA. 6-9 November 2014

In recent years, activation of the patient's immune system to defend against tumors was demonstrated to be a promising alternative strategy to classical cancer treatments. Dendritic cells (DCs) can present antigens on MHC-II and $-\mathrm{I}$ leading to the activation of $\mathrm{CD}_{4}^{+}$or $\mathrm{CD}^{+} \mathrm{T}$ cells, respectively. Stimulated $\mathrm{CD}^{+} \mathrm{T}$ cells act as helper cells for cytotoxic $\mathrm{CD}^{+} \mathrm{T}$ cells to kill tumor cells by mediating strong proliferation and licensing DCs, increasing their presentation capacity. Tumors bearing MHC-II molecules can also be directly destroyed by cytotoxic $\mathrm{CD}^{+} \mathrm{T}$ cells. As an efficient anti-tumor response strongly depends on the interplay of $\mathrm{DCs}, \mathrm{CD} 4^{+}$and $\mathrm{CD}^{+} \mathrm{T}$ cells, these three cell types are considered to be essential for successful immunotherapy design.

In clinical trials, DCs were either endogenously or exogenously loaded with tumor antigens for the presentation on MHC-I rather MHC-II. As the antigen presentation pathways differ, a simultaneous loading of MHC-I and -II was suboptimal. To overcome this obstacle, we used a signaling sequence (CrossTAg) to force MHC-II crosspresentation of tumor-associated antigens (TAAs) encoded by in vitro transcribed (ivt) RNA. Subsequently, peripheral blood lymphocytes were primed by DCs expressing TAAs on MHC-I and -II enabling activation and interaction of $\mathrm{CD}^{+}$and $\mathrm{CD} 8^{+} \mathrm{T}$ cells. By this approach, we were able to induce and identify TAA-specific $\mathrm{CD} 4^{+}$ and $\mathrm{CD}^{+} \mathrm{T}$ cells in the same experiment.

In addition, superior induction efficiency of DCs loaded with CrossTAg-TAA-ivtRNA compared to conventional TAA-ivtRNA was shown in the humanized NOD/scid IL2Rgnull (NSG) mouse model. NSG mice were engrafted with human peripheral blood mononuclear cells (PBMC) and vaccinated twice with DCs either transfected with CrossTAg-TAA-ivtRNA or conventional TAA-ivtRNA. Reisolated PBMC of mice vaccinated with CrossTAg-TAA-ivtRNA transfected DCs showed higher numbers of antigen-specific $\mathrm{CD}^{+}{ }^{+} \mathrm{T}$ cells and stronger activation/cytotoxic activity against tumor cells.

These in vitro and in vivo data illustrate the benefits of loading DCs with CrossTAg-linked target antigens as $\mathrm{CD}^{+}$and $\mathrm{CD}^{+}{ }^{+} \mathrm{T}$ cells can be induced side by side allowing interactions and $\mathrm{T}$ cell help.

\section{Authors' details \\ ${ }^{1}$ Trianta Immunotherapies GmbH - a subsidiary of Medigene AG, Germany. ${ }^{2}$ Institute of Molecular Immunology/Helmholtz Center Munich, Germany.}

Published: 6 November 2014

doi:10.1186/2051-1426-2-S3-P65

Cite this article as: Wehner et al: Generation of tumor antigen-specific CD4+ and CD8+ T cells by simultaneous MHC-I and -II epitope presentation in vitro and in vivo. Journal for ImmunoTherapy of Cancer 2014 2(Suppl 3):P65.

Trianta Immunotherapies GmbH - a subsidiary of Medigene AG, Germany Full list of author information is available at the end of the article 